\title{
Early outcomes of endoscopic transsphenoidal surgery for adult craniopharyngiomas
}

\author{
John A. Jane JR., M.D., ${ }^{1}$ Erin Kiehna, M.D., ${ }^{1}$ Spencer C. Payne, M.D., ${ }^{2}$ \\ Stephen V. Early, M.D., ${ }^{2}$ and Edward R. Laws JR., M.D. ${ }^{3}$ \\ ${ }^{1}$ Department of Neurosurgery and ${ }^{2}$ Department of Otolaryngology-Head and Neck Surgery, \\ University of Virginia Health System, Charlottesville, Virginia; and ${ }^{3}$ Department of Neurosurgery, \\ Brigham and Women's Hospital, Boston, Massachusetts
}

\begin{abstract}
Object. Although the transsphenoidal approach for subdiaphragmatic craniopharyngiomas has been performed for many years, there are few reports describing the role of the endoscopic transsphenoidal technique for suprasellar craniopharyngiomas. The purpose of this study was to report the outcomes of the endoscopic transsphenoidal approach for adults with craniopharyngiomas in whom the goal was gross-total resection.

Methods. Twelve patients were identified who were older than 18 years at the time of their pure endoscopic transsphenoidal surgery. Their medical records and imaging studies were retrospectively reviewed.

Results. Gross-total resection was achieved in $42 \%$ of cases when assessed by intraoperative impression alone and in $75 \%$ when assessed by the first postoperative MR imaging study. However, $83 \%$ of patients achieved at least a $95 \%$ resection when assessed by both intraoperative impression and the first postoperative MR imaging study. Permanent diabetes insipidus occurred postoperatively in $44 \%$ of patients. Six $(67 \%)$ of 9 patients who had a functioning hypothalamic-pituitary axis preoperatively developed panhypopituitarism after surgery. Visual improvement or normalization occurred in $78 \%$ of patients with preoperative visual deficits. Although no patient experienced a postoperative CSF leak, 1 patient was treated for meningitis.

Conclusions. The authors have achieved a high rate of radical resection and symptomatic improvement with the endoscopic transsphenoidal technique for both subdiaphragmatic (sellar/suprasellar) and supradiaphragmatic (suprasellar) craniopharyngiomas. However, this is also associated with a high incidence of new endocrinopathy. Endoscopic assessment of tumor resection may be more sensitive for residual tumor than the first postoperative MR imaging study. (DOI: 10.3171/2010.1.FOCUS09319)
\end{abstract}

\section{KEY WORDS • transsphenoidal}

-
$\mathrm{C}$ RANIOPHARYNGIOMAS are highly variable and complex benign tumors. They present in any age group with a variety of neurological, visual, and endocrinological symptoms. The tumors vary regarding the degree and character of calcification and may be cystic, solid, or a combination. Although many are limited to the sellar and suprasellar space, they can present either entirely within the sella or third ventricle. Such a protean tumor requires diverse treatment methods for its proper management. Although radical resection is possible for many tumors, others may require a more conservative approach consisting of limited resection followed by radiation therapy or intracavitary therapies.

A subset of tumors may also be managed using a transsphenoidal approach. The transsphenoidal approach for craniopharyngiomas is widely accepted for intrasellar craniopharyngiomas. Select centers have also advocated the transsphenoidal route for tumors with subdiaphragmatic origin and subsequent suprasellar extension., ${ }^{1,19,20}$ These subdiaphragmatic craniopharyngiomas are thought

Abbreviations used in this paper: DI $=$ diabetes insipidus; $\mathrm{GTR}=$ gross-total resection; IGF-I = insulin-like growth factor-I. to be more easily removed by a transsphenoidal approach because the expanded sella provides a widened aperture to the suprasellar compartment and also diaphragmatic protection from pial invasion. ${ }^{11,19}$ Although there is limited experience using the transsphenoidal approach for suprasellar tumors, $, 2,2,5,6$ endoscopic transsphenoidal approaches introduced over the past decade are being increasingly used., ${ }^{3,4,8-10,23}$ We describe our experience using the endoscopic transsphenoidal technique for adults with craniopharyngiomas and describe the neurological, endocrinological, and visual outcomes.

\section{Methods}

Inclusion criteria for the retrospective study included adult patients with craniopharyngiomas who underwent pure endoscopic transsphenoidal surgery. Between March 2005 and July 2009, 31 patients underwent transsphenoidal surgery for the treatment of a craniopharyngioma. Nineteen patients were excluded from the analysis. Nine patients were younger than 18 years of age, 6 adult patients underwent endoscopic-assisted microscopic resections, and 2 adults underwent purely microscopic 
TABLE 1: Presenting signs and symptoms in 12 patients who underwent endoscopic transsphenoidal surgery for a craniopharyngioma*

\begin{tabular}{|c|c|c|c|c|c|c|c|c|}
\hline \multirow{2}{*}{$\begin{array}{l}\text { Case } \\
\text { No. }\end{array}$} & \multirow{2}{*}{$\begin{array}{l}\text { Age (yrs), } \\
\text { Sex }\end{array}$} & \multirow[b]{2}{*}{ Previous Op } & \multirow{2}{*}{$\begin{array}{c}\text { Anterior Pituitary } \\
\text { Dysfunction }\end{array}$} & \multirow{2}{*}{$\begin{array}{l}\text { Perma- } \\
\text { nent DI }\end{array}$} & \multirow{2}{*}{$\begin{array}{l}\text { Visual } \\
\text { Deficit }\end{array}$} & \multicolumn{3}{|c|}{ Tumor Characteristics } \\
\hline & & & & & & Size (mm) & Type & Location \\
\hline 1 & $31.9, \mathrm{~F}$ & none & not & no & no & 17 & cystic & sellar/suprasellar \\
\hline 2 & 52.1, M & none & panhypopit & no & yes & 42.9 & mixed & sellar/suprasellar \\
\hline 3 & $29.5, \mathrm{M}$ & none & partial & yes & no & 17.9 & mixed & suprasellar \\
\hline 4 & $61.7, \mathrm{~F}$ & none & no & no & yes & 16 & cystic & sellar/suprasellar \\
\hline 5 & 53.3, M & craniotomy & partial & no & yes & 17.6 & solid & suprasellar \\
\hline 6 & 53.4, M & none & partial & no & no & 23.1 & mixed & suprasellar \\
\hline 7 & $76.6, \mathrm{~F}$ & none & panhypopit & no & yes & 29.2 & mixed & suprasellar \\
\hline 8 & $48.2, \mathrm{~F}$ & none & partial & yes & yes & 24 & mixed & sellar/suprasellar \\
\hline 9 & $54.2, \mathrm{~F}$ & none & partial & no & yes & 26.8 & cystic & suprasellar \\
\hline 10 & $60.9, \mathrm{~F}$ & transsphenoidal & partial & no & yes & 32.6 & mixed & sellar/suprasellar \\
\hline 11 & $43.0, \mathrm{M}$ & none & partial & no & yes & 21 & mixed & suprasellar \\
\hline 12 & $45.6, \mathrm{~F}$ & transsphenoidal & panhypopit & yes & yes & 16.5 & mixed & suprasellar \\
\hline
\end{tabular}

procedures. Of the 14 adult patients who underwent pure endoscopic transsphenoidal resections, 2 were excluded. One patient was lost to follow-up and another had mixed pathology (adrenocorticotropic hormone adenoma and craniopharyngioma). With approval from our local institutional review board, the medical records and imaging studies were reviewed.

All patients underwent neurological and endocrinological evaluations prior to and after surgery. Those patients with visual signs or symptoms also underwent pre- and postoperative ophthalmological examinations including formal visual field testing. Women who were taking oral contraceptives, who were postmenopausal, or who had undergone a hysterectomy were excluded from analysis of postoperative gonadal function.

Maximal tumor diameter was measured on preoperative imaging studies and was measured as the largest diameter in the coronal, axial, or sagittal planes. Tumors were categorized as cystic, solid, or mixed based on their predominant features. If a tumor was primarily cystic but had a small solid nodule, the tumor was considered cystic. By contrast, a primarily solid tumor that had a small cystic component was considered mixed. Tumors were also categorized according to location. Tumors were considered subdiaphragmatic in origin if the tumor expanded the sellar bone. If the tumor had a small component within the sella but had not expanded the bony confines of the sella, the tumor was considered suprasellar.

The degree of resection was determined by a combination of the intraoperative assessment and the 2- or 3-month postoperative MR imaging studies. Resections were considered gross total only if the surgical impression and MR imaging assessment revealed no residual tumor. Resections were categorized as radical if both the surgical impression and the postoperative MR imaging study indicated that at least $95 \%$ of the tumor was resected. A subtotal resection was considered one in which at least $50 \%$ of the tumor was removed, and a partial resection indicated that more than $50 \%$ of the tumor remained.

\section{Results}

\section{Study Population and Clinical Presentation}

Of the 12 patients who underwent pure endoscopic surgery, there were 7 women and 5 men with a mean age of 50.77 years (range 29-76 years) (Table 1 ). The mean age of the women (54 years) was older than that of the men (46 years). The mean follow-up was 13.29 months with a range of 1.8-44.67 months. Three patients had undergone previous surgical treatment, 2 of whom had undergone previous transsphenoidal surgery for presumed pituitary adenomas at outside facilities and 1 had undergone a previous craniotomy. No patient had received radiation therapy prior to endoscopic transsphenoidal surgery.

Nine $(75 \%)$ of 12 patients reported visual deficits as the presenting symptom (Table 1). A bitemporal hemianopia was the most common visual field deficit encountered. One patient was diagnosed on evaluation for DI, and 2 patients were diagnosed incidentally. One of these 2 patients was diagnosed on evaluation for a syncopal episode and another during workup of a left-sided thalamic stroke. Headache was a common symptom and was present in 10 $(83 \%)$ of the 12 patients.

Diabetes insipidus was present in 3 patients $(25 \%)$ prior to surgery (Table 1). By contrast, at least partial anterior pituitary dysfunction was common preoperatively, being present in $10(83 \%)$ of 12 patients. Three patients developed panhypopituitarism preoperatively. All men were found to have low testosterone levels. Two of the women were taking oral contraceptives, and therefore, their gonadal function was not evaluable. Of the 5 women who could be evaluated, 3 were postmenopausal and 1 had had 


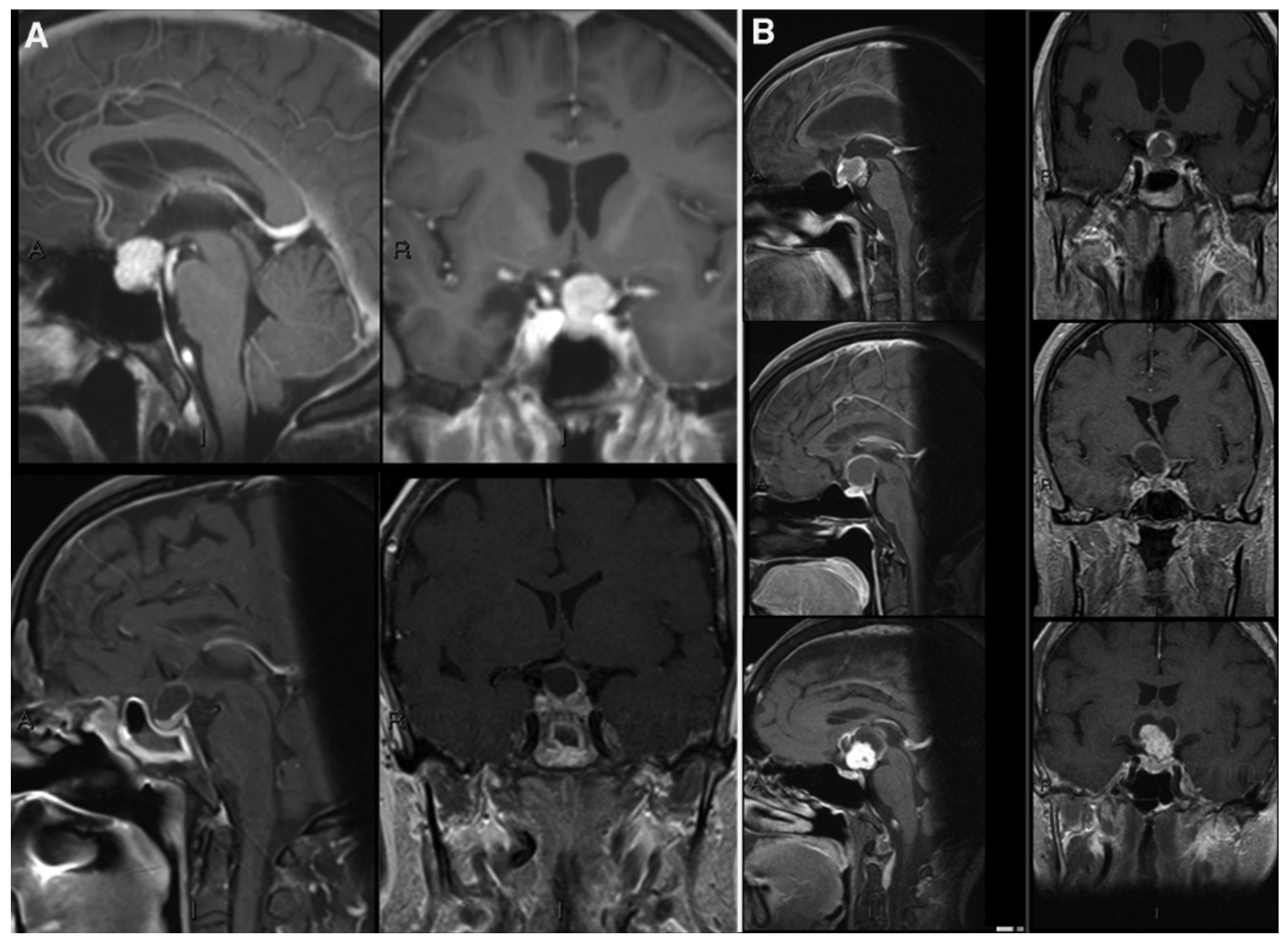

FIG. 1. Sagittal and coronal T1-weighted MR imaging with Gd of subdiaphragmatic (A) and supradiaphragmatic (B) tumors.

a hysterectomy. Gonadotroph deficiency (inappropriately low luteinizing hormone and follicle-stimulating hormone levels) was present in 3 of the 5 evaluable women. Somatotroph deficiency (low IGF-I levels) was found in 7 $(58 \%)$ of 12 patients, thyrotroph deficiency was present in $6(50 \%)$, and corticotroph deficiency was seen in $3(25 \%)$.

\section{Imaging Features}

No tumor was confined to the sella (Table 1). Five tumors had suprasellar extension that presented with an expanded sella, and the tumors were considered to have a subdiaphragmatic origin (Fig. 1A). Two of these tumors extended into the third ventricle. Among the 7 supradiaphragmatic craniopharyngiomas, 2 extended into the third ventricle (Fig. 1B). The mean maximal diameter was $23.7 \mathrm{~mm}$ (range 16-43 $\mathrm{mm}$ ). The subdiaphragmatic tumors were larger on average (mean $26.5 \mathrm{~mm}$, range $16-43 \mathrm{~mm}$ ) than the suprasellar tumors (mean $21.73 \mathrm{~mm}$, range $16.5-29 \mathrm{~mm}$ ). One tumor was solid, 3 were primarily cystic, and the remaining 9 tumors were mixed.

\section{Surgical Approach}

All patients underwent a purely endoscopic transsphe- noidal approach that included a binarial 3-hand technique with wide anterior sphenoidotomy and partial posterior septectomy. In 9 operations (6 of 7 supradiaphragmatic suprasellar tumors and 3 of 5 subdiaphragmatic tumors), the opening was extended across the tuberculum sellae to include the planum sphenoidale to provide greater access to the suprasellar space. Neuronavigation was used in 10 of 12 cases. None of our patients required lumbar drainage intraoperatively or postoperatively. We encountered a CSF leak in all 12 patients. In 1 patient with a subdiaphragmatic sellar/suprasellar tumor, the leak was closed with a thin layer of dural substitute over the diaphragm. In another case, the defect was closed using a vascularized nasoseptal flap. ${ }^{17}$ In the remaining 11 operations a large CSF leak was encountered, which was most often closed using abdominal fat (in 11 patients) held in place using a rigid buttress (in 10). ${ }^{21}$ This closure was bolstered in 9 cases by also filling the sphenoid sinus with fat, while in 1 the sphenoid sinus was filled with DuraSeal.

\section{Surgical Outcome}

The average length of stay following surgery was 3.3 days (range 2-6 days). A GTR was achieved in 5 patients $(41.67 \%), 5(41.67 \%)$ were assessed as having a radical re- 
TABLE 2: Surgical outcomes*

\begin{tabular}{cclllll}
\hline $\begin{array}{c}\text { Case } \\
\text { No. }\end{array}$ & $\begin{array}{c}\text { Tumor } \\
\text { Size }(\mathrm{mm})\end{array}$ & \multicolumn{1}{c}{ Location } & Pathological Subtype & $\begin{array}{c}\text { Resection } \\
\text { by MRI }\end{array}$ & $\begin{array}{c}\text { Resection by Endo- } \\
\text { scopic Inspection }\end{array}$ & Visual Outcome \\
\hline 1 & 17 & sellar/suprasellar & adamantinomatous & GTR & radical & remained normal \\
\hline 2 & 42.9 & sellar/suprasellar & adamantinomatous & GTR & radical & improved to VFF \\
\hline 3 & 17.9 & suprasellar & not specified & GTR & GTR & remained normal \\
\hline 4 & 16 & sellar/suprasellar & adamantinomatous & GTR & GTR & improved to VFF \\
\hline 5 & 17.6 & suprasellar & papillary & subtotal & radical & no improvement \\
\hline 6 & 23.1 & suprasellar & adamantinomatous & GTR & radical & remained normal \\
\hline 7 & 29.2 & suprasellar & papillary & GTR & radical & improved to VFF \\
\hline 8 & 24 & sellar/suprasellar & papillary & GTR & GTR & improved to VFF \\
\hline 9 & 26.8 & suprasellar & adamantinomatous & radical & radical & normalized \\
\hline 10 & 32.6 & sellar/suprasellar & adamantinomatous & subtotal & subtotal & no improvement \\
\hline 11 & 21 & suprasellar & papillary & GTR & GTR & improved to VFF \\
\hline 12 & 16.5 & suprasellar & adamantinomatous & GTR & GTR & normalized \\
\hline * VFF $=$ visual fields full to confrontation. & & & & \\
$\dagger$ Objective improvement by formal visual field testing but not dramatic. Deficits remain on confrontation testing.
\end{tabular}

section (> 95\% removal), and $2(16.67 \%)$ had partial removals (Table 2). Therefore, $83 \%$ of patients (10 of 12) experienced at least a $95 \%$ removal of their tumors. Both patients with subtotal resections had undergone previous surgery. Interestingly, postoperative MR imaging at 2-3 months was less sensitive at discerning small residual tumors than the intraoperative endoscopic inspection. Whereas the initial MR imaging indicated that at GTR had been achieved in 9 patients (75\%), our intraoperative endoscopic impression was that a GTR had only been achieved in 5 (41.67\%) (Figs. 2 and 3, Videos 1 and 2). The follow-up is too short (mean 13.29 months, range $1.8-44.67$ months) to draw conclusions as to whether intraoperative endoscopic impression or postoperative MR imaging will be more predictive of recurrence.

VIDEO 1. Incomplete resection. Intraoperative endoscopic views using the $0^{\circ}$ and then the $45^{\circ}$ endoscopes. The remaining tumor is progressively removed. A portion of the cyst wall is densely adherent to the optic chiasm and could not be removed. Using the $45^{\circ}$ endoscope, the residual wall is seen adherent to the optic chiasm but confirms removal from the third ventricle wall. Both Monro foramina are visible.

VIDEO 2. Complete removal. Intraoperative endoscopic views using the $0^{\circ}$ and then the $45^{\circ}$ endoscopes. After separating the tumor from the posterior aspect of the optic chiasm, its attachment to the third ventricle is sharply divided. Using the $45^{\circ}$ endoscope, the tumor bed is inspected and no residual tumor is evident. Both Monro foramina and the cerebral aqueduct as well as the anterior cerebral arteries are visible.

Patients in whom GTR was achieved as assessed by both intraoperative impression and first postoperative MR imaging had smaller tumors than those in whom GTR was not achieved (19.08 vs $27.03 \mathrm{~mm})$. However, when the degree of resection was assessed by initial postoperative MR imaging alone, the mean tumor size in patients who underwent GTR was only marginally smaller than all other resections ( 23.07 vs $25.67 \mathrm{~mm}$ ). There was no difference in the rate of resection for subdiaphragmatic sellar/suprasellar (GTRs in 2 of 5, GTRs as noted on MR imaging in 4 of 5) versus suprasellar tumors (GTRs in 3 of 7, GTRs as noted on MR imaging in 5 of 7.

Review of the pathological findings in 11 of our 12 cases revealed 7 adamantinomatous and 4 papillary tumors (Table 2). The remaining case was not characterized by neuropathology. There did not appear to be a difference in the rate of resection according to subtype. We achieved at least a 95\% resection of 6 of the 7 adamantinomatous craniopharyngiomas based on intraoperative assessment and first postoperative MR imaging (2 GTRs and 4 radical resections). Similarly, there was at least a $95 \%$ resection in 3 of the 4 papillary variants (2 GTRs and 1 radical resection).

All patients with at least 95\% resection are undergoing follow-up with serial imaging and without adjuvant therapy. One of the 2 patients who underwent a subtotal resection received postoperative fractionated radiotherapy and experienced subsequent reduction in tumor volume (Fig. 4). Craniotomy was recommended for the other patient. However, this patient preferred serial imaging and has experienced visual deterioration and progressive tumor growth during follow-up (Fig. 5).

\section{Endocrine Outcomes}

Three of our patients had preoperative DI. Of the remaining 9 patients, 4 (44\%) experienced new persistent DI following surgery (Table 3). Another patient experienced transient DI, which resolved by the first follow-up visit at 2 months. None of our patients experienced normalization of an anterior pituitary deficiency after surgery. All 3 patients who had panhypopituitarism still suffered from the condition postoperatively. Six (67\%) of 9 patients who did not have panhypopituitarism preoperatively developed the condition. Two patients without preoperative anterior pituitary dysfunction appear to have maintained 


\section{Endoscopic transsphenoidal resection of adult craniopharyngioma}
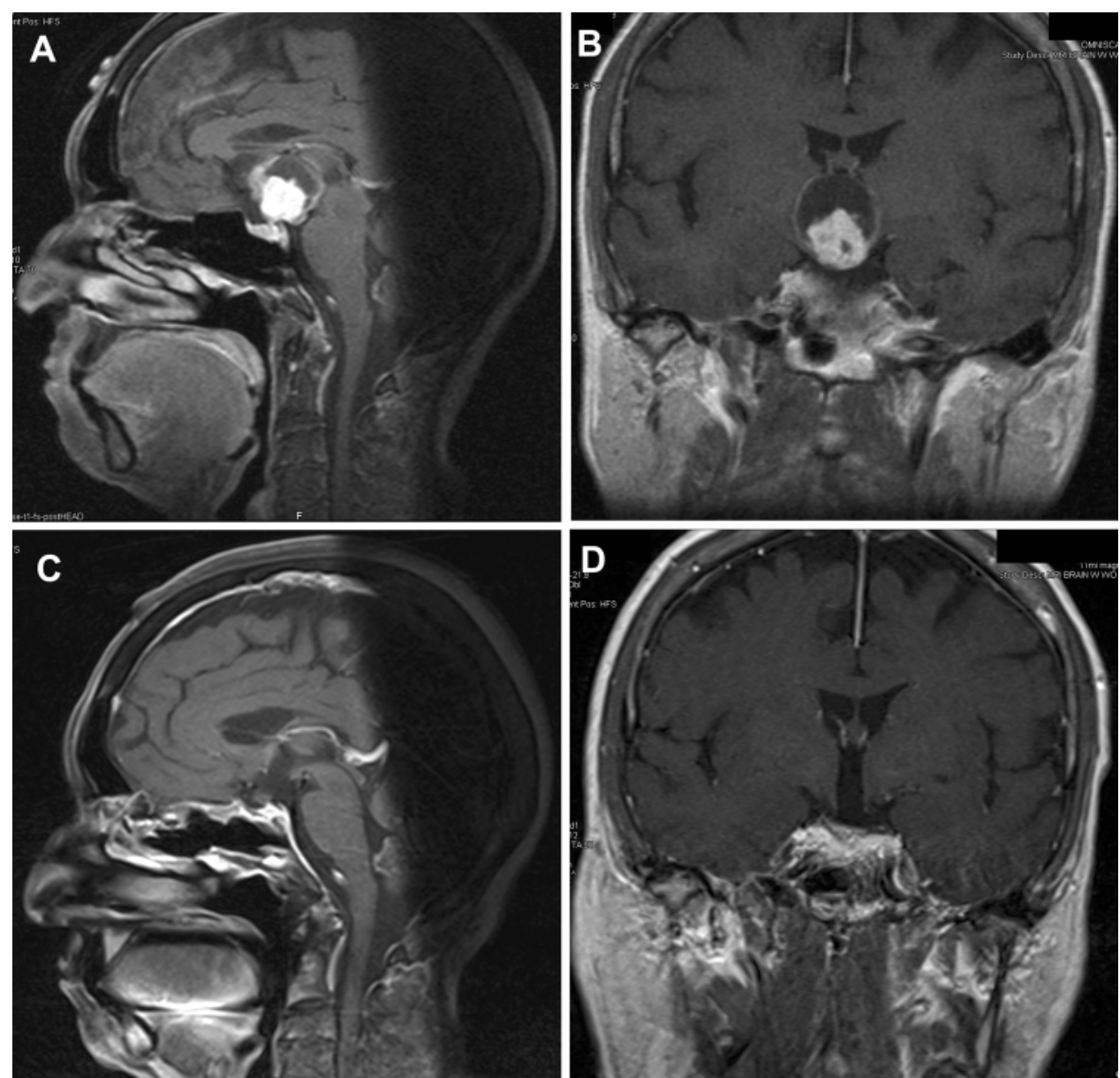

FIG. 2. Complete resection by initial postoperative MR imaging but incomplete removal by endoscopic surgical assessment. A and B: Preoperative sagittal and coronal T1-weighted MR images. C and D: Postoperative sagittal and coronal T1weighted MR imaging showing apparent complete resection. However, intraoperative endoscopic inspection indicated residual tumor (see Video 1).

normal function postoperatively (one was taking oral contraceptive and could not be assessed, and the other did not have a postoperative IGF-I level to confirm somatotroph function). One patient with partial anterior pituitary dysfunction did not experience new deficits postoperatively. Overall, the incidence of new thyrotroph deficiency was $67 \%$ (4 of 6), and new adrenal insufficiency was 67\% (6 of 9) (Table 4). All male patients continued to have gonadal dysfunction and were placed on replacement therapy. Of the 5 patients with normal preoperative IGF-I levels, 1 became deficient and 2 remained normal. Two others did not have postoperative IGF-I levels assessed. If these patients were assumed to have become deficient, then the incidence of new somatotroph deficiency would be $60 \%$ (3 of 5$)$.

\section{Visual Outcomes}

None of the 3 patients with normal vision preoperatively experienced visual deterioration (Table 2). Of the 9 patients with preoperative visual deficits, in 2 patients there was normalization of their vision and in 5 patients the examination improved to full visual fields to confrontation with subtle persistent deficits on formal visual field testing. Two patients reported improvement, but on formal visual field testing the improvements were minimal and these patients were categorized as unchanged. One of these patients, who had undergone a subtotal resection, experienced subsequent tumor regrowth and recurrent visual deficits. Therefore, although all patients objectively experienced visual improvement at initial follow-up, 78\% (7 of 9) experienced either substantial improvement or normalization.

\section{Perioperative Complications}

Perioperative complications occurred in one-third of the patients. Although no patient experienced a postoperative CSF leak, 1 patient experienced meningitis within 48 hours of surgery, which was confirmed by lumbar puncture and required antibiotics. Two patients who had been sent home on a regimen of desmopressin were readmitted for treatment of hyponatremia 3 weeks after surgery. One of these patients was also treated with antibiotics for sinusitis, which resolved by the 2-month follow-up. Two patients reported memory difficulties. One of these patients had undergone prior craniotomy and had neuropsychological testing prior to transsphenoidal surgery, 

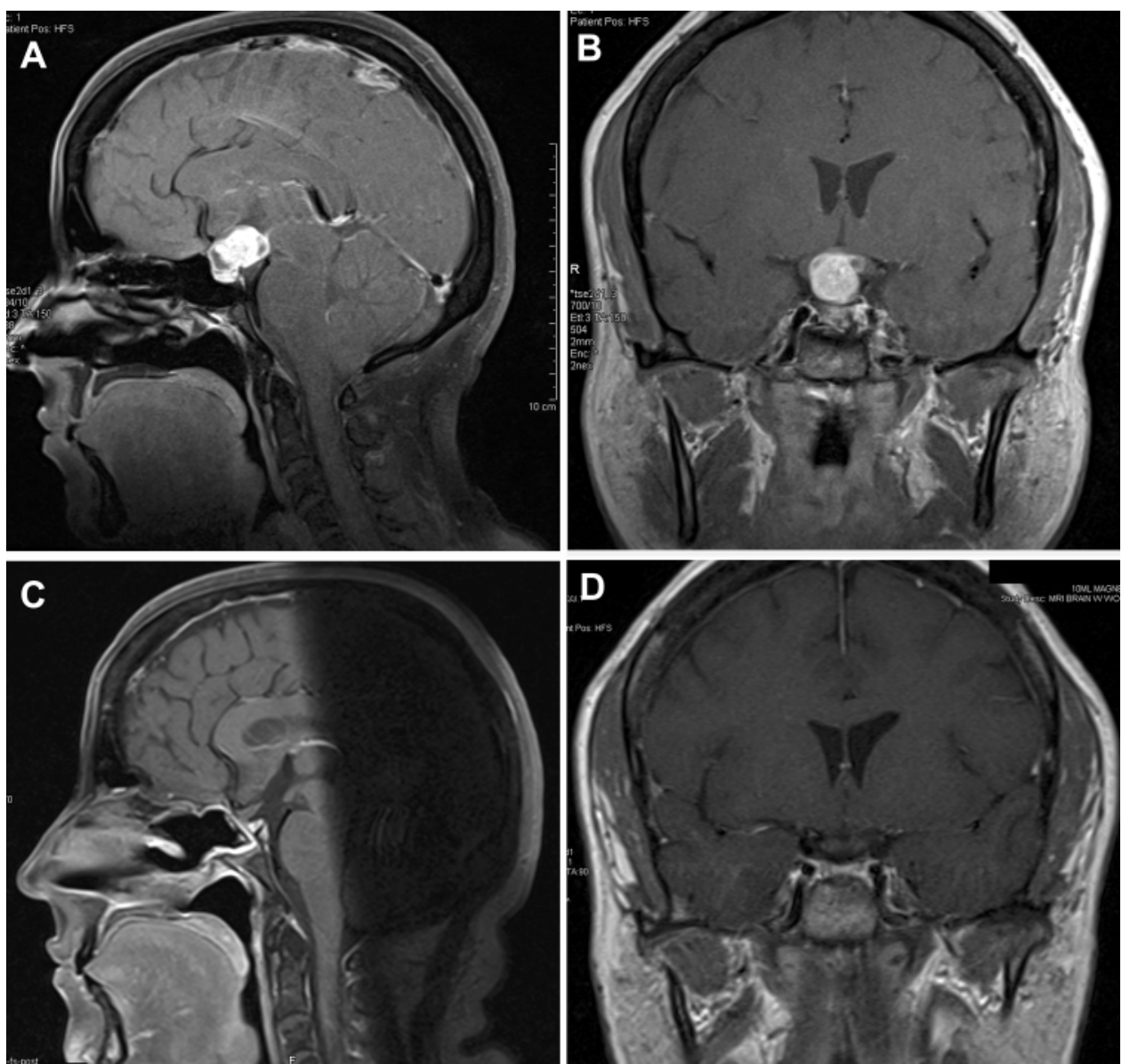

FIG. 3. Complete resection by initial postoperative MR imaging is confirmed with intraoperative endoscopic assessment. A and B: Preoperative sagittal and coronal T1-weighted MR images. C and D: Postoperative sagittal and coronal T1-weighted MR images showing complete resection. Intraoperative endoscopic inspection indicated complete resection (see Video 2).

confirming that the deficits predated the transsphenoidal operation. The other patient had experienced a thalamic stroke prior to transsphenoidal surgery. We did not perform preoperative cognitive testing, and therefore, some of the deficits could be related to the surgery.

\section{Discussion}

Although the transsphenoidal approach for the resection of craniopharyngiomas is not new, its application has traditionally been restricted to either intrasellar tumors or those with subdiaphragmatic origin because of the expanded sellar corridor and the protection from pial invasion from the diaphragmatic cuff., 1,7,20,22 Following the introduction of the extended transsphenoidal transplanum approach by Martin Weiss in the late 1980s, centers have begun to approach select suprasellar craniopharyngiomas through a transsphenoidal approach. ${ }^{2-6,8,9,16,25}$ Our early results would suggest that in adults, the approach provides good outcomes for both subdiaphragmatic sellar/ suprasellar and suprasellar craniopharyngiomas. No difference in the rate of resection was appreciated between these 2 groups in our series.

Previous studies have suggested that intraoperative assessment of the degree of resection underestimates the amount of residual tumor and that postoperative MR imaging is more accurate. This has been evidenced by the rate of recurrence after apparent GTR. ${ }^{12,13,24,26}$ In this se-

TABLE 3: Preoperative and postoperative DI and panhypopituitarism

\begin{tabular}{cclll}
\hline $\begin{array}{c}\text { Case } \\
\text { No. }\end{array}$ & Preop DI & Postop DI & $\begin{array}{c}\text { Preop } \\
\text { Panhypopit }\end{array}$ & $\begin{array}{c}\text { Postop } \\
\text { Panhypopit }\end{array}$ \\
\hline 1 & no & no & no & no \\
2 & no & no & yes & yes \\
3 & yes & yes & no & yes \\
4 & no & no & no & no \\
5 & no & yes & no & yes \\
6 & no & yes & no & yes \\
7 & no & yes & yes & yes \\
8 & yes & yes & no & yes \\
9 & no & yes, transient & no & no \\
10 & no & no & no & yes \\
11 & no & yes & no & yes \\
12 & yes & yes & yes & yes \\
total & 3 & 7 persistent & 3 & 9 \\
\hline
\end{tabular}



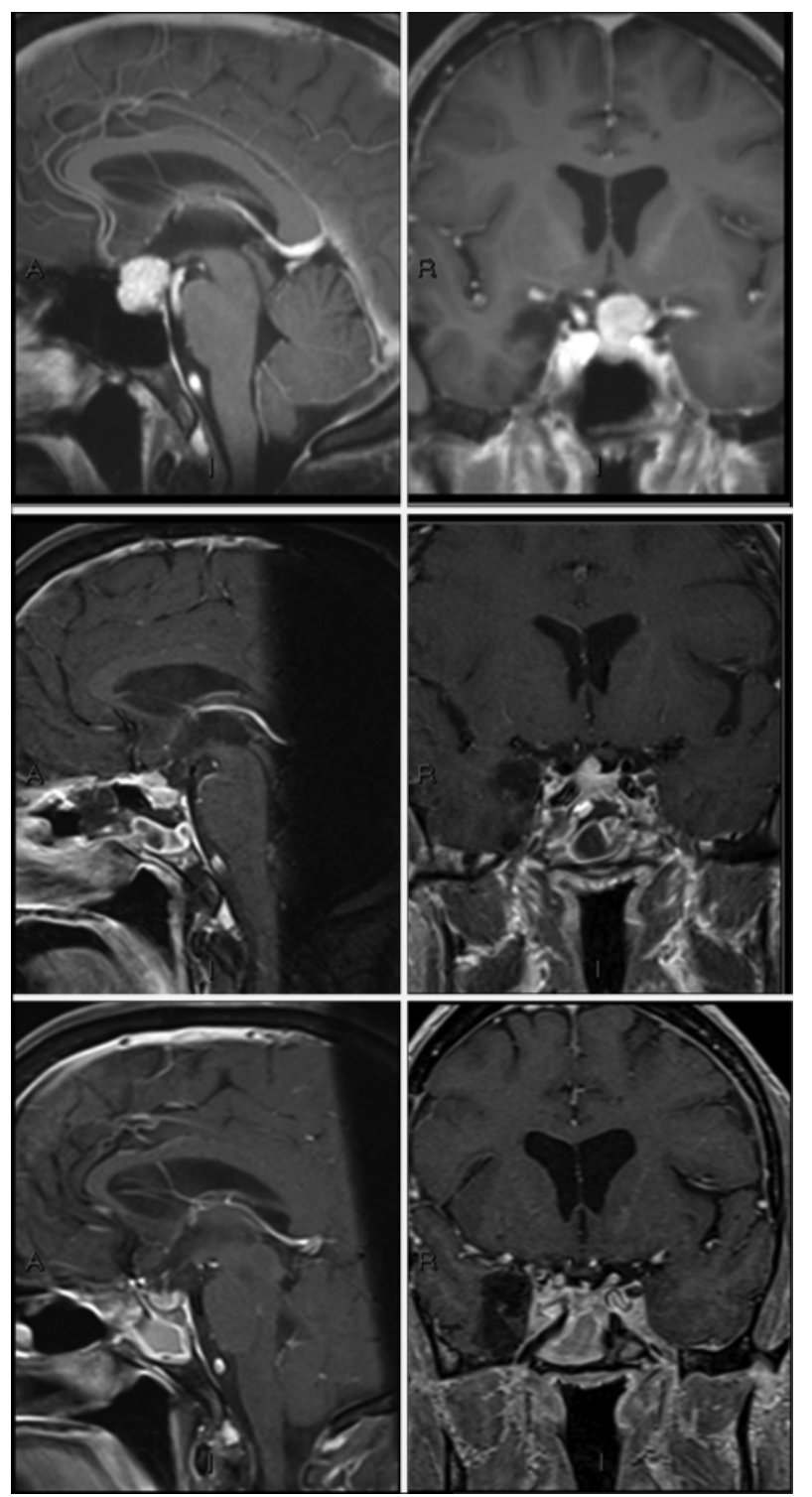

FIG. 4. Sagittal and coronal Gd-enhanced T1-weighted MR images showing the preoperative (upper) and postoperative (center) tumor volumes and after radiotherapy (lower).

ries, the surgeon's intraoperative endoscopic assessment was a more sensitive indicator of a small residual tumor than the initial postoperative MR imaging findings. Whereas by endoscopic assessment 5 patients had undergone GTR and 6 had undergone a radical resection, the first postoperative MR imaging study indicated that GTR had been achieved in 9 and radical resection had been achieved in 1. The short follow-up of this series does not allow conclusions to be drawn as to which (intraoperative endoscopic assessment or postoperative MR imaging) will be more clinically relevant regarding recurrence.

If the initial postoperative MR image is considered alone, our results are comparable to previous rates of resection of craniopharyngiomas by the microscopic transsphenoidal approach. Gross-total resection as determined by postoperative MR imaging was achieved in $83 \%$ of patients in this series. This compares favorably to previ-
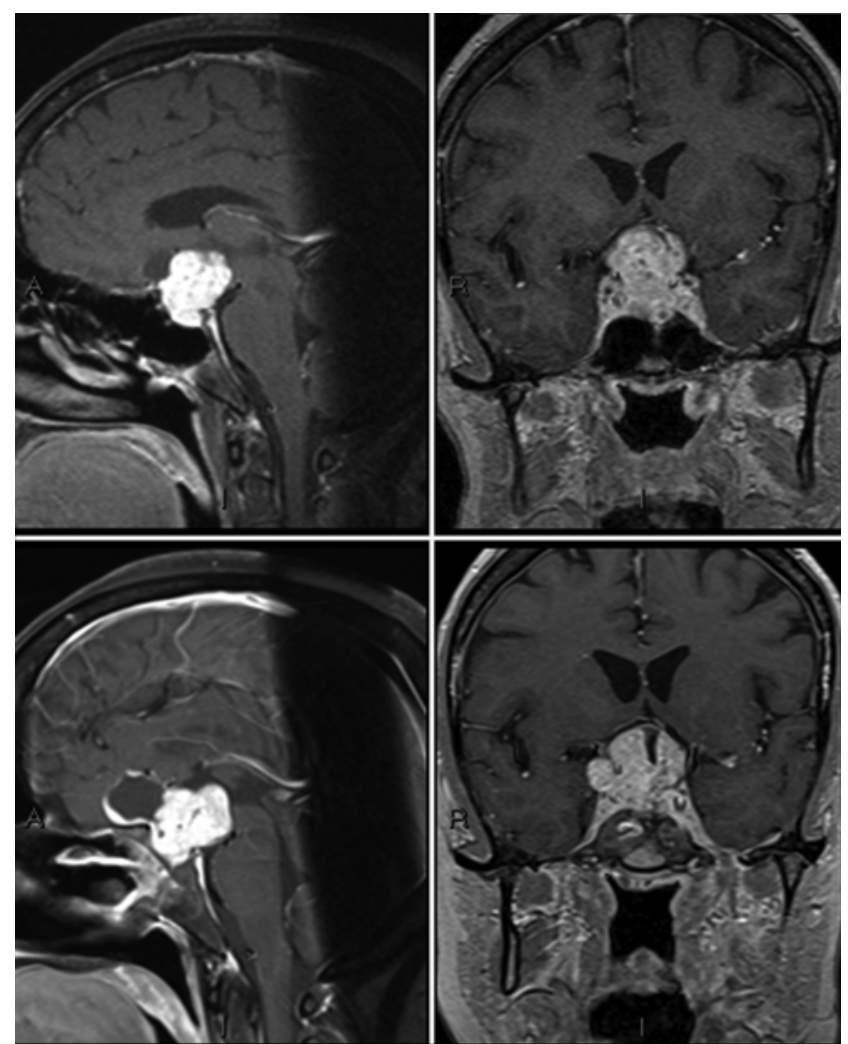

FIG. 5. Sagittal and coronal Gd-enhanced T1-weighted MR images obtained in a patient who presented with a large cystic and solid tumor (upper) and experienced progressive growth (lower) for which she declined further treatment.

ous reports that have indicated a GTR rate between 47 and $90 \%$ when performed using the microscope. . $^{1,2,15,20,22}$ As has been noted in previous studies, transsphenoidal surgery does appear less effective for tumors that have been previously treated. ${ }^{7,15,20}$ In our series, both patients who experienced subtotal resections had been treated previously (one by craniotomy and the other by transsphenoidal surgery).

For select tumors, the transsphenoidal approach effectively decompresses the optic chiasm and restores function. In our series, $78 \%$ of patients experienced either normalization or improvement to full fields by confrontation testing. These results are consistent with previous microscopic transsphenoidal series in which visual improvement occurred in 60-100\%. . $^{1,9,15,18}$

The transsphenoidal approach does cause pituitary dysfunction in a large number of patients. New DI occurred in $44 \%$ of our patients, and $67 \%$ experienced new panhypopituitarism. None of our patients experienced a gain in pituitary function. Most centers have reported results consistent with this series. New DI has been reported to occur in 39-67\% of patients who have undergone microscopic transsphenoidal resections. ${ }^{1,6,14,15}$ Anterior pituitary dysfunction has been reported in 22-75\%.,14,15,18

The design of this study does not allow a definitive assessment of the comparative efficacy of the endoscopic and microscopic transsphenoidal approaches. The poten- 
TABLE 4: Preoperative and postoperative anterior pituitary deficiencies*

\begin{tabular}{|c|c|c|c|c|c|c|c|c|c|}
\hline \multirow[b]{2}{*}{ Case No. } & \multirow[b]{2}{*}{ Sex } & \multicolumn{2}{|c|}{ ACTH } & \multicolumn{2}{|c|}{$\mathrm{TSH}$} & \multicolumn{2}{|c|}{ Gonadal } & \multicolumn{2}{|c|}{ IGF-I } \\
\hline & & Preop & Postop & Preop & Postop & Preop & Postop & Preop & Postop \\
\hline 1 & $F$ & 0 & 0 & 0 & 0 & $\mathrm{OCP}$ & OCP & 0 & 0 \\
\hline 2 & M & 1 & 1 & 1 & 1 & 1 & 1 & 0 & 0 \\
\hline 3 & M & 0 & 1 & 0 & 1 & 1 & 1 & 0 & 1 \\
\hline 4 & $F$ & 0 & 0 & 0 & 0 & 0 & NT & 0 & NT \\
\hline 5 & M & 0 & 1 & 1 & 1 & 1 & 1 & 1 & 1 \\
\hline 6 & $M$ & 0 & 1 & 1 & 1 & 1 & 1 & 0 & NT \\
\hline 7 & $F$ & 1 & 1 & 0 & 1 & 1 & NT & 1 & 1 \\
\hline 8 & $\mathrm{~F}$ & 0 & 1 & 1 & 1 & 1 & 1 & 1 & 1 \\
\hline 9 & $F$ & 0 & 0 & 0 & 1 & 0 & NT & 1 & 1 \\
\hline 10 & $\mathrm{~F}$ & 0 & 1 & 1 & 1 & 1 & 1 & 1 & 1 \\
\hline 11 & M & 0 & 1 & 1 & 1 & 1 & 1 & 1 & NT \\
\hline 12 & $\mathrm{~F}$ & 1 & 1 & 0 & 1 & $\mathrm{OCP}$ & OCP & 1 & 1 \\
\hline total & & 3 & 9 & 6 & 10 & & & 7 & \\
\hline
\end{tabular}

* $\mathrm{ACTH}=$ adrenocorticotropic hormone; $\mathrm{TSH}=$ thyroid-stimulating hormone; 0 = no deficiency in function; 1 = deficiency; OCP = oral contraceptives; NT = not tested.

tial advantages of the endoscope center on the panoramic view of the operative field. Unlike the microscope, which is limited by line of sight, the endoscope provides angled views that allow a more precise visualization of the suprasellar space and the relation of the tumor to critical neurovascular structures. This appeared to translate to a more critical assessment of the degree of resection. Despite these apparent advantages, the endoscopic rate of resection and its visual and endocrine outcomes are not definitively superior to those of the results of previously published microscopic transsphenoidal series. Although this may relate to selection bias, it may also be that although the endoscope provides a wider view of the operative field, it also is limited by a lack of true 3D views, instruments that can access what is visualized by the angled endoscopes, and a more cramped operative corridor because of the lack of a nasal speculum.

\section{Conclusions}

The endoscopic transsphenoidal approach for adult craniopharyngiomas allows for a high rate of radical resection with reliable visual improvement. New pituitary deficits do occur in the majority of patients with a low rate of major complications. The improved visualization with the endoscope may provide a more sensitive indicator of postoperative residual tumor than the initial postoperative MR imaging.

\section{Disclosure}

The authors report no conflict of interest concerning the materials or methods used in this study or the findings specified in this paper.

Author contributions to the study and manuscript preparation include the following. Conception and design: JA Jane Jr. Acquisition of data: JA Jane Jr., E Kiehna, SC Payne, SV Early. Analysis and interpretation of data: JA Jane Jr. Drafting the article: JA Jane Jr., ER Laws. Critically revising the article: JA Jane Jr.,
E Kiehna, ER Laws. Reviewed final version of the manuscript and approved it for submission: JA Jane Jr., E Kiehna, ER Laws. Administrative/technical/material support: JA Jane Jr.

\section{References}

1. Chakrabarti I, Amar AP, Couldwell W, Weiss MH: Longterm neurological, visual, and endocrine outcomes following transnasal resection of craniopharyngioma. J Neurosurg 102:650-657, 2005

2. Couldwell WT, Weiss MH, Rabb C, Liu JK, Apfelbaum RI, Fukushima T: Variations on the standard transsphenoidal approach to the sellar region, with emphasis on the extended approaches and parasellar approaches: surgical experience in 105 cases. Neurosurgery 55:539-550, 2004

3. de Divitiis E, Cappabianca P, Cavallo LM, Esposito F, de Divitiis O, Messina A: Extended endoscopic transsphenoidal approach for extrasellar craniopharyngiomas. Neurosurgery 61 (5 Suppl 2):219-228, 2007

4. de Divitiis E, Cavallo LM, Cappabianca P, Esposito F: Extended endoscopic endonasal transsphenoidal approach for the removal of suprasellar tumors: part 2. Neurosurgery 60:46-59, 2007

5. Dusick JR, Esposito F, Kelly DF, Cohan P, DeSalles A, Becker DP, et al: The extended direct endonasal transsphenoidal approach for nonadenomatous suprasellar tumors. J Neurosurg 102:832-841, 2005

6. Dusick JR, Fatemi N, Mattozo C, McArthur D, Cohan P, Wang $\mathrm{C}$, et al: Pituitary function after endonasal surgery for nonadenomatous parasellar tumors: Rathke's cleft cysts, craniopharyngiomas, and meningiomas. Surg Neurol 70:482-491, 2008

7. Fahlbusch R, Honegger J, Paulus W, Huk W, Buchfelder M: Surgical treatment of craniopharyngiomas: experience with 168 patients. J Neurosurg 90:237-250, 1999

8. Frank G, Pasquini E, Doglietto F, Mazzatenta D, Sciarretta V, Farneti G, et al: The endoscopic extended transsphenoidal approach for craniopharyngiomas. Neurosurgery 59 (1 Suppl 1):ONS75-ONS83, 2006

9. Gardner PA, Kassam AB, Snyderman CH, Carrau RL, Mintz $\mathrm{AH}$, Grahovac S, et al: Outcomes following endoscopic, expanded endonasal resection of suprasellar craniopharyngiomas: a case series. J Neurosurg 109:6-16, 2008 


\section{Endoscopic transsphenoidal resection of adult craniopharyngioma}

10. Gardner PA, Prevedello DM, Kassam AB, Snyderman CH, Carrau RL, Mintz AH: The evolution of the endonasal approach for craniopharyngiomas. J Neurosurg 108:10431047,2008

11. Hardy J: Transsphenoidal hypophysectomy. J Neurosurg 34:582-594, 1971

12. Hoffman HJ: Surgical management of craniopharyngioma. Pediatr Neurosurg 21 (Suppl 1):44-49, 1994

13. Hoffman HJ, De Silva M, Humphreys RP, Drake JM, Smith ML, Blaser SI: Aggressive surgical management of craniopharyngiomas in children. J Neurosurg 76:47-52, 1992

14. Honegger J, Buchfelder M, Fahlbusch R: Surgical treatment of craniopharyngiomas: endocrinological results. J Neurosurg 90:251-257, 1999

15. Honegger J, Buchfelder M, Fahlbusch R, Däubler B, Dörr HG: Transsphenoidal microsurgery for craniopharyngioma. Surg Neurol 37:189-196, 1992

16. Kaptain GJ, Vincent DA, Sheehan JP, Laws ER Jr: Transsphenoidal approaches for the extracapsular resection of midline suprasellar and anterior cranial base lesions. Neurosurgery 49:94-101, 2001

17. Kassam AB, Thomas A, Carrau RL, Snyderman CH, Vescan A, Prevedello D, et al: Endoscopic reconstruction of the cranial base using a pedicled nasoseptal flap. Neurosurgery 63 (1 Suppl 1):ONS44-ONS53, 2008

18. Kitano M, Taneda M: Extended transsphenoidal surgery for suprasellar craniopharyngiomas: infrachiasmatic radical resection combined with or without a suprachiasmatic translamina terminalis approach. Surg Neurol 71:290-298, 2009

19. Laws ER Jr: Transsphenoidal microsurgery in the management of craniopharyngioma. J Neurosurg 52:661-666, 1980
20. Laws ER Jr: Transsphenoidal removal of craniopharyngioma. Pediatr Neurosurg 21 (Suppl 1):57-63, 1994

21. Leng LZ, Brown S, Anand VK, Schwartz TH: "Gasket-seal" watertight closure in minimal-access endoscopic cranial base surgery. Neurosurgery 62 (5 Suppl 2):ONSE342-ONSE343, 2008

22. Maira G, Anile C, Rossi GF, Colosimo C: Surgical treatment of craniopharyngiomas: an evaluation of the transsphenoidal and pterional approaches. Neurosurgery 36:715-724, 1995

23. Schwartz TH, Anand VK: The endoscopic endonasal transsphenoidal approach to the suprasellar cistern. Clin Neurosurg 54:226-235, 2007

24. Villani RM, Tomei G, Bello L, Sganzerla E, Ambrosi B, Re T, et al: Long-term results of treatment for craniopharyngioma in children. Childs Nerv Syst 13:397-405, 1997

25. Weiss MH: The transnasal transsphenoidal approach, in Apuzzo MLJ (ed): Surgery of the Third Ventricle. Baltimore: Williams and Wilkins, 1987, pp 476-494

26. Yaşargil MG, Curcic M, Kis M, Siegenthaler G, Teddy PJ, Roth P: Total removal of craniopharyngiomas. Approaches and long-term results in 144 patients. J Neurosurg 73:3-11, 1990

Manuscript submitted December 15, 2009.

Accepted January 13, 2010.

Address correspondence to: John A. Jane Jr., M.D., Department of Neurosurgery, University of Virginia Health System, Charlottesville, Virginia 22908. email: johnjanejr@virginia.edu. 